\title{
Jacques Boncompain, De Scribe à Hugo. La condition de l'auteur (1815-1870)
}

\section{Valentina Ponzetto}

\section{(2) OpenEdition}

1 Journals

\section{Édition électronique}

URL : http://journals.openedition.org/studifrancesi/4381

DOI : 10.4000/studifrancesi.4381

ISSN : 2427-5856

Éditeur

Rosenberg \& Sellier

\section{Édition imprimée}

Date de publication : 1 septembre 2016

Pagination : 332-333

ISSN : 0039-2944

\section{Référence électronique}

Valentina Ponzetto, « Jacques Boncompain, De Scribe à Hugo. La condition de l'auteur (1815-1870) »,

Studi Francesi [En ligne], 179 (LX | II) | 2016, mis en ligne le 01 septembre 2016, consulté le 18 septembre 2020. URL : http://journals.openedition.org/studifrancesi/4381 ; DOI : https://doi.org/ 10.4000/studifrancesi.4381

Ce document a été généré automatiquement le 18 septembre 2020.

\section{(c)}

Studi Francesi è distribuita con Licenza Creative Commons Attribuzione - Non commerciale - Non opere derivate 4.0 Internazionale. 


\title{
Jacques Boncompain, De Scribe à Hugo. La condition de l'auteur (1815-1870)
}

\author{
Valentina Ponzetto
}

\section{RÉFÉRENCE}

JACQUES BONCOMPAIN, De Scribe à Hugo. La condition de l'auteur (1815-1870), préface de Laurent Petitgirard, président de la SACEM et de Jean-Claude Bologne, président de la SGDL, Paris, Honoré Champion, 2013, 832 pp.

1 Jacques Boncompain est juriste, historien, auteur dramatique et membre de la Société des Auteurs et Compositeurs Dramatiques (SACD), qui lui a ouvert ses archives et l'a activement soutenu pour la rédaction de cet ouvrage monumental, consacré à l'histoire des droits d'auteur en France et des associations qui les défendent. De Scribe à Hugo. La condition de l'auteur (1815-1870), est le premier volet d'un diptyque complété par De Dumas à Marcel Pagnol. Les auteurs aux temps modernes (1871-1996) (2014). Les deux volumes profitent d'une riche documentation, tirée principalement des archives de la SACD, mais aussi des archives familiales de Beaumarchais, des archives de la ComédieFrançaise, des Archives nationales et des fonds de nombreuses bibliothèques parisiennes.

2 Une mise en garde préalable s'impose: bien que le titre ne l'indique pas clairement, il s'agit essentiellement d'une histoire de la SACD et de ses combats pour la défense des auteurs dramatiques contre les plagiaires, la contrefaçon, la censure, les directeurs de théâtre et les acteurs. Le but de l'auteur a été de «remonter aux origines de sa [de la SACD] constitution et de voir comment s'est mise en place une administration qui introduisit une révolution dans les rapports entre auteurs, directeurs des théâtres et usagers» (p. 27). Certes, les autres associations de protection des droits d'auteur créées sur son modèle, la Société des Gens de Lettres (SGDL, fondée en 1838) et la Société des 
auteurs, compositeurs et éditeurs de musique (SACEM, fondée en 1851) sont également évoquées, mais la focalisation principale reste sur le monde du théatre et sur les dramaturges qui, depuis Beaumarchais, ont entrepris des démarches légales et associatives pour la protection des intérêts pécuniaires à tirer de ce qu'aujourd'hui on appelle la «propriété intellectuelle». Aussi, l'ouvrage se signale-t-il principalement à l'attention des spécialistes de l'histoire du théâtre et de l'industrie du spectacle au XIX siècle, et pourrait décevoir, par exemple, les spécialistes du roman ou de la presse.

La conception du volume est linéaire, chronologique, organisée en quatre grands chapitres divisés selon la succession des régimes politiques sur la période prise en examen: la Restauration (ch. I), la Monarchie de Juillet (ch. II), la deuxième République (ch. III), le Second Empire (ch. IV). L'évolution politique, sociale et culturelle sous les quatre régimes est bien entendu prise en compte dans son influence sur le marché littéraire, quoique sans doute d'une manière moins détaillée qu'on aurait pu le souhaiter d'un ouvrage de ces proportions. Signalons au passage que le Second Empire, longuement discrédité par les historiens, est vu par Jacques Boncompain d'un œil favorable, comme une période de grand développement des spectacles et de rayonnement inégalé du répertoire français à l'étranger. Une introduction, qu'il serait sans doute plus approprié d'appeler "prologue», évoque le tableau de la répartition des recettes au XVIII ${ }^{\mathrm{e}}$ siècle et les interventions radicales et fondatrices de Beaumarchais, Framery et Fillette-Loraux, sous Louis XVI, puis pendant la Révolution, pour assurer des lois sur la propriété dramatique et la création d'une structure capable d'en assurer le respect. Il s'agira d'abord du Bureau de Législation dramatique, ensuite du Bureau des Auteurs, enfin de la Société des Auteurs et Compositeurs Dramatiques, formée le 7 mars 1829.

4 Parallèlement à l'histoire de l'institution, suivie parfois de manière presque annalistique, c'est surtout l'aspect matériel de la «condition de l'auteur» qui est examiné: contrats avec les théâtres et avec les agences de perception des droits, démêlés avec la censure ou avec les plagiaires, combat pour l'établissement, puis l'extension des droits d'auteur post mortem, création d'une caisse de secours pour les auteurs dans le besoin, représentations à bénéfice. L'ensemble est touffu, dense, parfois très technique dans l'évocation d'aspects juridiques et économiques de la gestion des droits d'auteur, parfois étonnamment narratif, voire anecdotique à la manière des historiens et des critiques du xix ${ }^{e}$ siècle. Il faudrait tout de même nuancer quand on cite Eugène de Mirecourt plutôt que Jean-Claude Yon pour évoquer les faits et gestes de Scribe!

5 Par sa densité et par le nombre de précieux documents transcrits et référencés, cet ouvrage est destiné à devenir un usuel de référence pour tous ceux qui s'intéressent au théâtre du xix $\mathrm{x}^{\mathrm{e}}$ siècle. Citons notamment l'intérêt des Annexes, où l'on trouvera, entre autres, des tableaux récapitulatifs des lois et règlements relatifs aux droits d'auteurs, les noms et les années d'activités des agents de perception, le texte de projets de lois sur la propriété littéraire, les statuts de la SACD, ou le texte du traité proposé aux auteurs par le théâtre du Gymnase en 1842. Une certaine dimension militante de l'ouvrage, qui ne perd pas l'occasion de souligner l'importance pour un auteur de pouvoir vivre de sa plume, en pleine liberté et indépendance, ou les risques du plagiat et de la contrefaçon, n'a certes pas perdu d'actualité en ce début de xxI ${ }^{e}$ siècle. 